\title{
Isotope Fractionation Factors of Dawsonite -Tracing the Formation Environment
}

GYÖRGY CZUPPON* ${ }^{1}$, BetTINA PURGSTALleR ${ }^{2}$, MARTIN DIETZEL $^{2}$, DÓRA CSERESZNYÉS ${ }^{3}$, ALBERT LEIS ${ }^{5}$, ATTILA DEMÉNY ${ }^{1}$, DÓRA KESJÁR ${ }^{1}$, IVETT KOVÁCS ${ }^{1}$, CSILlA KIRÁLY $^{4}$, CSABA SZABÓ ${ }^{3}$, GYÖRGY FALUS ${ }^{3}$

${ }^{1}$ Institute for Geological and Geochemical Research, RCAES, Budaörsi út 45, Budapest, H-1112, Hungary, czuppon@geochem.hu

${ }^{2}$ Institute of Applied Geosciences, Graz University of Technology, Rechbauerstraße 12, Graz, A-8010, Austria

${ }^{3}$ Lithosphere Fluid Research Lab, Eötvös Loránd University, Pázmány Péter sétány 1/C., Budapest, H-1117, Hungary

${ }^{4}$ Geographical Institute, RCAES, Budaörsi út 45, Budapest, H-1112, Hungary

${ }^{5}$ JR-AquaConSol GmbH, Steyrergasse 21, 8010, Graz, Austria

Dawsonite $\left[\mathrm{NaAlCO}_{3}(\mathrm{OH})_{2}\right]$ is formed in $\mathrm{CO}_{2}$-rich environments and used as an indicator for $\mathrm{CO}_{2}$ infiltration in geological reservoirs. Hence, the isotopic composition of dawsonite can help to (i) constrain the origin of the fluid from which it was formed and (ii) provide information about the chemical and physical processes, which control carbonate dissolution and precipitation during $\mathrm{CO}_{2}$ infiltration. The most widely used tools serving information about conditions of dawsonite formation are stable carbon and oxygen isotope signatures. However, interpretation of isotope data is strongly limited as isotope fractionation factors for the dawsonite-fluid system are not known.

In order to determine the fractionation factors for stable carbon, oxygen, and hydrogen isotopes between dawsonite and precipitating solution, syntheses were performed at $100^{\circ} \mathrm{C}$, $150^{\circ} \mathrm{C}$, and $175^{\circ} \mathrm{C}$ with different isotopic compositions of the solutions. Thus, besides classical carbon and oxygen analyses, the hydrogen isotopic composition of structural $\mathrm{OH}^{-}$of dawsonite was measured by LGR LWIA-24d type laser analyzer attached to a special inlet system. In the present contribution ${ }^{13 / 12} \mathrm{C},{ }^{18 / 16} \mathrm{O}$ and $\mathrm{D} / \mathrm{H}$ fractionation factors for dawsonite are presented and discussed to calculate the formation temperature and/or the composition of the parent fluid for naturally formed dawsonite. In addition, the ${ }^{18 / 16} \mathrm{O}$ vs. D/H "dawsonite-line" has been established.

The research was financially supported by NKFIH project (no.: K-131353 for Gy. Falus). 